\title{
Os Regulamentos Independentes
}

CLENfCIO DA SILVA DUARTE

Consultor Jurídico do DASP

\section{SUMÁRIO}

1- Introdução: 1. Os três Podêres do Estado. Funções que Ihes correspondem. 2. Atos respectivos: pontos-de-vista formal e material. Interêsse prático da distinção. 3. Ato legislativo, em sentido material. 4. Conceito de ato administrativo, sob o mesmo aspecto. 5. Idem, em relação ao ato jurisdicional.

II - O Regulamento em Geral: 6. Duas grandes categorias: internos ou administrativos e externos ou jurídicos. 7. Classificação dos regulamentos externos. 8. Natureza jurídica intrínseca do regulamento em geral. Sua conceituação como ato materialmente legislativo.

III - O Regulamento Independente: 9. Falta de estudos sôbre a espécie, no direito brasileiro. 10. Impugnação, no pais, à existência do regulamento independente, sob alegação de que não encontra guarida no Direito Constitucional brasileiro. 11. Fundamento do regulamento independente. 12. Refutação às críticas. $\mathrm{Na}$ expressão - "para fiel execução das leis" - não se entende, apenas, a competência regulamentar executiva, que se prende a uma certa e determinada lei anterior, mas poder regulamentar amplo. 13. Exemplos de regulamentos independentes e matéria sôbre que dispõem. 14. Previsão Constitucional, decorrente da Emenda Constitucional n? 1, de 1969, e do Ato Institucional $n \div 8$, de 1969, da competência do Executivo para baixar amplamente regulamentos independentes. 15. Conclusão. 


\section{I - INTRODUÇÃO}

1. As atividades estatais se desenvolvem através de três Podêres, cuja divisão é o princípio basilar da organização do Estado Constitucional moderno: o Legislativo, o Executivo e o Judiciário. E as funções que lhes correspondem, na separação tripartida de Podêres, são, respectivamente, a legislativa, a administrativa e a jurisdicional.

Como adverte SEABRA FAGUNDES, 1 enquanto a função legislativa se situa na fase de formação do Direito, as demais atuam na de sua realização, eis que legislar nada mais é do que editar o direito positivo, isto é, elaborar normas de caráter geral e abstrato para regular a vida em sociedade; administrar, aplicar a lei de ofício, ou seja, sem incidência do processo contencioso, e julgar, aplicar a lei, vale dizer, as normas que integram o direito objetivo, contenciosamente. ${ }^{2}$

Se cada uma dessas funções possui a sua atividade própria, daí se não infere, todavia, que os órgãos respectivos tenham a exclusividade da função que nominalmente thes corresponde, pois se, no caso brasileiro, o princípio é o de proibir-se delegação de atribuições, êste sofre restrições, por fôrça de ressalvas expressamente previstas na Constituição. ${ }^{3}$ e 4

Para a inteligência dessa observação, é preciso dar o conceito formal e material dos atos funcionais.

2. A distinção dos atos públicos, em seus aspectos formais e materiais, apresenta evidente interêsse prático, bastando citar como exemplo, entre nós, como na maioria dos países, o não

1 Contrôle dos Atos Administrativos pelo Poder Judiciário, 2a ed., Río de Janeiro, no 2, pág. 13.

2 Segundo DUGUIT (Manuel de Droit Constitutionnel, 2a ed., Paris, 1911, $\S 28$, pág. 85), "pela função legislativa, o Estado formula o direito objetivo ou o põe em execução; pela função administrativa, o Estado cria uma situação de direito subjetivo ou condiciona, por um ato individual, o nascimento de uma situação legal; pela função jurisdicional, o Estado constata a existência e a extensão de uma regra de direito ou de uma situação de direito, em caso de violação ou contestação, e ordena as medidas necessárias para
assegurar-lhe o respeito".

3 Const. Fed., art. $6 \circ$, parágrafo único, na redação dada pela Emenda Constitucional n? 1, de 1969.

4. A Independência e harmonia dos Podêres não devem induzir a que se trate de compartimentos estanques, pois o que há, na realidade, é uma interpenetração, entendendo-se essa independência em têrmos, sem que se confira à palavra uma acepção rígida, que impossibilite a participação de um no processo de execuçẩo do outro. Do contrário se impediria a harmonia 
se admitir recurso ao Judiciário contra o ato legislativo material em tese, ${ }^{5}$ quando necessàriamente não o seria sob o ponto-de-vista formal. O mesmo não aconteceria, verbi gratia, se o ato, embora legislativo no seu aspecto formal, fôsse materialmente administrativo.

O ponto-de-vista formal, também chamado subjetivo ou orgânico, é considerado segundo o órgão de que emana o ato. Nesse sentido, todo e qualquer ato originário do Poder Legislativo será legislativo; do Executivo, administrativo, e do Judiciário, jurisdicional, embora sob o aspecto material possam não ter a mesma classificação.

O conceito material tem em atenção a natureza jurídica intrínseca do ato, o que êle é em sua essência, ontològicamente. Assim, são atos administrativos materiais, por exemplo, o provimento de cargos da Secretaria da Câmara dos Deputados e do Senado Federal ${ }^{6}$, bem como idêntica competência em relação aos tribunais ${ }^{7}$, embora, do ponto-de-vista formal, como esclarecido, tais atos sejam, respectivamente, legislativo e jurisdicional.

Como assinala DUGUIT ${ }^{8}$, a distinção é extremamente simples, ainda que a aplicação seja, não raro, delicada.

Se a conceituação do ato, sob o aspecto formal, é evidente, pois basta atentar para o órgão de que emana, a caracterização material exige a análise da natureza jurídica interna do ato, segundo seus efeitos no domínio do direito subjetivo ou do direito objetivo, abstraindo-se do órgão de que se origina.

3. Na lição do grande mestre francês, "todos os atos emanados do Estado que contêm uma regra possuem, do ponto-de-vista material, o caráter legislativo". " Para SEABRA FAGUNDES, "lei, no sentido material, é o ato jurídico emanado do Estado com o caráter de norma geral, abstrata e obrigatória, tendo como finalidade o ordenamento da vida coletiva. Êstes caracteres, e o de modificação na ordem jurídica preexistente, que decorre da sua qualidade de ato jurídico, se somam para caracterizar a lei entre os demais atos do Estado. Mas entre êles só é específico o de generalidade". 10

5 Cf. DUGUIT, Leçons de Droit Public Général, Paris, 1926, pág. 160.

6 Const. Fed., art. 30, caput.

7 Idem, art. 115, n? II.

8 Ob. cit., pág. 158.

9 Leçons cits., pág. 161.

10 Ob. cit., págs. 30 e 31 . 
4. Ato Administrativo, em sentido material, é o que produz efeitos de direito, no sentido de estabelecer ou declarar uma situação jurídica subjetiva. ${ }^{11}$

5. Encarado sob o mesmo aspecto, o ato jurisdicional oferece maiores dificuldades em sua caracterização, como admitem eminentes tratadistas. ${ }^{12}$ Não cabe, neste trabalho, a indagação de tais dificuldades, pelo que passamos a conceituá-lo como aquêle em que o Estado, provocado contenciosamente, resolve uma questão de direito. ${ }^{13}$

\section{II - O REGULAMENTO EM GERAL}

6. Dados os conceitos, do ponto-de-vista material, dos atos estatais, examinemos o que interessa mais objetivamente ao presente estudo, fixando, por conseguinte, a natureza jurídica intrínseca do regulamento, não sem antes esclarecer que êste se divide em duas grandes categorias: interno e externo.

A distinção entre regulamentos internos e externos, segundo esclarece ZANOBINI ${ }^{14}$, corresponde à feita pela doutrina alemã entre regulamentos administrativos e regulamentos jurídicos ${ }^{15}$ : os primeiros com o objetivo de disciplinar a atividade

11 SEABRA FAGUNDES, ob. cit., pág. 37, define os atos administrativos como "aquêles através dos quais o Estado determina situaçöes jurídicas individuais ou concorre para a sua formação". Essa conceituação não nos parece completa, porquanto nela se não incluiriam os atos administrativos meramente declaratórios de direito, tais como a apostila, a certidão, etc., que nem determinam situaçőes jurídicas individuais, nem concorrem para a sua formação, limitando-se, apenas, a reconhecê-las, o que, entretanto, não deixa de produzir um efeito jurídico, embora simplesmente declaratório.

12 Cf. DUGUIT, Leçons cits., págs. 176 e 177; GABINO FRAGA, Derecho Administrativo, $5^{a}$ ed., México, 1952, pág. 51.

13 Ainda o grande mestre brasileiro, SEABRA FAGUNDES (ob. cit., pág. 97), conceitua o ato jurisdicional, sob o aspecto material, como "aquêle através do qual 0 Estado define $e$ determina situações jurídicas individuais com o fim de remover, pela definitiva interpretação do direito, conflito surgido a propósito de sua aplicação". Essa definição, além de englobar os dois aspectos formal e material, pois que seria ininteligivel sem que o ato se originasse de órgão do Poder Judiciário, ainda se refere à "definitiva interpretação do direito", o que determina, de logo, a exclusã̃o dêsse conceito dos atos jurisdicionais recorriveis, que, não dando a definitiva interpretação do direito, não deixam, todavia, de ser atos jurisdicionais em sentido material.

14 GUIDO ZANOBINI, Corso di Diritto Amministrativo, $8^{a}$ ed., Milăo, 1958, vol. I, pág. 68 .

15 GARCÓN Y MARIN, Tratado de Derecho Administrativo 12a ed., Madrid, 1952, tomo I, pág. 104, se mostra contrário à classificação alemã dos regulamentos em jurídicos e administrativos, pois, segundo êle: "o regulamento é criador de normas jurídicas; há direito objetivo em todos êles, tanto nos denominados jurídicos quanto nos administrativos"... 
interna dos órgãos, ao passo que os segundos têm por finalidade constituir nôvo direito objetivo para os cidadãos, bem como disciplinar as relações entre êstes e a Administração.

7. Deixando de lado os regulamentos internos ou administrativos, que se baseiam, apenas, no dizer de ZANOBINI ${ }^{16}$, no "poder de auto-organização inerente a qualquer instituição e na supremacia que esta tem sôbre os seus próprios componentes" ${ }^{17}$, classifiquemos os regulamentos externos ou jurídicos.

Embora haja inúmeras classificações dos regulamentos externos, segundo vários critérios, a mais importante é a tradicional distinção, de acôrdo com a finalidade, em executivos ou de execução, delegados e independentes ou autônomos.

Os primeiros se prendem a uma lei determinada, de que derivam, visando a esclarecê-la, para facilitar-lhe a execução; os regulamentos delegados se originam de disposição legal que Ihes outorga a faculdade de dispor sôbre matéria de que trata a lei delegante, embora com a prerrogativa, não inteligível no regulamento de execução, de estatuir normas não contempladas na lei, ainda que dentro do âmbito de atuação dela; os regulamentos independentes ou autônomos, ao contrário dos dois anteriores, dispõem livremente sôbre matéria não-disciplinada por qualquer lei. ${ }^{18}$

8. Se, do ponto-de-vista formal, o regulamento 19 é sempre um ato administrativo, sob o aspecto material não há unanimidade de conceituação, havendo eminentes juristas que não

16 Corso, cit., vol. I, pág. 167.

17 Se os regulamentos externos ou jurídicos, entre nós, só podem ser baixados pelo Chefe do Poder Executivo, os internos ou administrativos podem emanar de outras autoridades, quer formalmente administrativas, quer legislativas ou judiciárias (regimentos internos de entidades da Administração Direta e Indireta, de Tribunais, da Câmara dos Deputados e do Senado Federal, etc.).

18 Para ZANOBINI, Corso, cit., vol. I, págs. 72 e 73 , "os regulamentos executivos ou de execução se prendem sempre a uma lei precedente e têm - objetivo de estabelecer as normas particulares necessárias à sua execução. Tais normas têm, evidentemente, o caráter de normas secundárias em relação às primárias derivadas da lei. Os regulamentos independentes pressupõem, ao contrário, um simples poder discricionário atribuído pela lei ao Poder Executivo em relação a determinada matéria, que, por êsse efeito, vem a ser disciplinada ùnicamente pelas normas do regulamento: estas, por isso, têm caráter de normas jurídicas primárias. Os regulamentos delegados não são uma terceira categoria, mas uma subespécie das outras duas".

19 Sempre que se falar, de agora em diante, em regulamento, sem adjetivação, entende-se que se cogita do regulamento externo ou jurídico. 
aceitam a natureza legislativa do regulamento. Inclinamo-nos pela corrente oposta, que tem em LÉN DUGUIT um dos seus mais notáveis defensores. 20

Em nosso entender, talvez a razão dos opositores esteja em que consideram apenas os regulamentos de execução, que têm a finalidade de complementar as leis, emitindo apenas normas secundárias, com o que não criam direito nôvo. Mesmo quanto a tais regulamentos, entendemos não se lhes poder negar, ainda que se trate de atos complementares, a característica de lei material, do momento em que apresentam o elemento específico desta, que é a generalidade, além da abstração. ${ }^{21}$

Se atentarmos, todavia, para os chamados regulamentos independentes ou autônomos, não é possivel negar-lhes a acentuada característica de lei material, sem mencionar os regulamentos delegados, que inovam juridicamente, embora intra legem.

O poder regulamentar não se esgota com os simples regulamentos de execução. Sua competência transcende dêstes, para alcançar ainda os chamados regulamentos independentes ou autônomos e os regulamentos delegados.

\section{III - O REGULAMENTO INDEPENDENTE}

9. A literatura brasileira a respeito do poder regulamentar não é das mais desenvolvidas, havendo apenas uma ou outra referência, sem um estudo mais aprofundado. Dai, em nosso entender, a confusão freqüentemente encontrada até mesmo entre os nossos maiores especialistas.

20 Cf. Manuel de Droit Constitutionnel, cit., págs. 107 e segs., Leçons de Droit Public Général, também cit., págs. 168 e segs.

21 GABINO FRAGA, Derecho Administrativo, cit., pág. 129, sôbre a identificação do regulamento, materialmente, com a lei, afirma que aquêle, como todos os atos de índole legislativa, cria, modifica ou extingue situações jurídicas gerais, para mais adiante (págs. 130 e 131), refutando o argumento de que a subordinação do regulamento à lei impediria sua conceituação como ato materialmente administrativo, ponderar: "Com efeito, se o papel do regulamento é facilitar a aplicação da lei, lògicamente tem que implicar a existência anterior desta, e necessàriamente tem que conformar-se aos seus preceitos, já que não poderia bem cumprir seu objetivo se, para tornar prática a execução da lei, ao invés de moldar-se a suas disposições, as contrariasse. Por outra parte, essa situação subordinada do regulamento não ordinária não perde sôbre sua natureza jurídica, do mesmo modo que a lei dinar-se à Constitu seu caráter legislativo pelo fato de que tenha que subordade com a própria 
O melhor estudo sôbre a matéria, feito na vigência da Carta Política de 1937, é do Ministro VICTOR NUNES LEAL. ${ }^{22}$ Mas, pelos objetivos do trabalho, não são apreciadas em maior profundidade as várias espécies de regulamento.

Já no direito estrangeiro, a matéria tem merecido maior atenção, quer dos constitucionalistas, quer dos especialistas em Direito Administrativo.

Abstraindo-se dos regulamentos de execução, que, no dizer de PIETRO VIRGA, "são os que pressupõem a existência de lei precedente que regule a matéria e a que necessàriamente se prendem com o objetivo de the explicar o conteúdo, com disposições particulares e minuciosas, garantindoIhe e providenciando-lhe a exata e uniforme aplicação" ${ }^{23}$, bem como os regulamentos delegados, passemos a examinar os regulamentos independentes ou autônomos, objeto precípuo dêste trabalho.

10. Não são de pequena monta as objurgatórias, quer na doutrina pátria, quer na alienígena, à existência do regulamento independente ou autônomo. E a razão dessas impugnações se situa em que o regulamento independente só se autorizaria por fôrça de norma constitucional que expressamente o previsse ou atribuísse ao Poder Executivo, de maneira explícita, tal regulamentação.

OSWALDO ARANHA BANDEIRA DE MELLO, ao caracterizar os regulamentos independentes como os que se constituem em "regras normativas, gerais, abstratas e impessoais, promulgadas pelo Executivo" e que "correspondem a verdadeiras leis, pouco importando o órgão que os emana", entende que só se justificam quando oriundos de podêres confiados diretamente ao Executivo pelo Direito Constitucional, legislado ou costumeiro. ${ }^{24}$

Segundo o emérito professor paulista, no direito brasileiro, "ao Executivo só se admitem os regulamentos externos executivos, secundum legem, e os regulamentos externos autorizados ou delegados, intra legem". ${ }^{25}$ Mais incisivo é, ainda, o eminente professor da Faculdade de Direito de São Paulo, GERALDO ATALIBA, quando, advertindo sôbre a má

22 Lei e Regulamento, in R.D.A., vol. I, págs. 371 e segs.

23 Diritto Costituzionale, 3a ed., Palermo, 1955, pág. 392.

24 Principios Gerais de Direito Administrativo, Rio, Forense, 1969, vol. I, pág. 127.

25 Ob. e vol. cits., pág. 313. 
importação da doutrina estrangeira, sem condições de vicejar no país, fulmina de nulo, por inconstitucional, o regulamento independente, desde que a faculdade regulamentar deferida ao Poder Executivo só se entende no que respeita à fiel execução das leis. 26

11. Não nos parece procedente a impugnação que se oferece à existência do regulamento independente sem norma constitucional que expressamente o autorize. 0 regulamento independente se justifica onde a lei deixa à Administração uma certa gama de livre atividade, originando-se da competência discricionária ${ }^{27}$, que nada mais é do que um juizo de conveniência e oportunidade, entregue à exclusiva apreciação da autoridade administrativa competente, tendo em vista a finalidade do ato a praticar-se.

Em nosso direito, sempre existiu e se justificou o regulamento independente, quando a matéria sôbre que verse se inclua no âmbito do poder discricionário ${ }^{28}$, pacificamente reconhecido à Administração.

O regulamento independente não se origina da necessidade de baixar normas, secundum legem, sem criação de direito nôvo, para fiel execução das leis (regulamento de execução), ou de delegação expressa legal para estatuir complementação legislativa criadora de direito nôvo, embora intra legem (regulamento delegado) ${ }^{29}$, pois que o regulamento autônomo, ainda que não tenha podêres derrogatórios de nor-

26 Apontamentos de Ciência das Finanças, Direito Financeiro e Tributário, São Paulo, Revista dos Tribunais, 1969, págs. 132 a 134.

27 Para GARCIA OVIEDO, Derecho Administrativo, 9a ed., atualizada e ampliada por ENRIQUE MARTINEZ USEROS, Madrid, 1968, vol. I, pág. 245, "agir discricionàriamente equivale a agir livremente, ainda que acomodando a conduta a um fim público específico: fim fiscal, fim de policia, etc.". E, mais adiante (pág. 246): "A diferença entre ato discricionário e ato arbitrário percebe-se claramente: é uma diferença teleológica. $O$ ato discricionário se converte em ato arbitrário, quando a Administração não ajusta sua conduta ao fim em vista do qual a lei o autorizou. Por exemplo, se a Administração realizou um ato autorizado por uma lei de policia ou de sanidade com um
fim fiscal ou político. É o caso do chamado desvio de poder introduzido pelo direito francês e que deu origem a um interessantíssimo recurso judicial".

28 "O poder discricionário não se exerce à margem da Lei, mas é um meio de aplicar a Lei, e é, por outro lado, necessário, para evitar que o funcionário se converta num robot" (DI QUAL, La Compétence Liée, Paris, 1964, págs. 20 e 595, apud GARCIA OVIEDO, ob. e vol. cits., pág. 247, nota 8).

29 O regulamento delegado não se confunde com legislação delegada, porquanto esta é competência legislativa plena, dentro da matéria sôbre que delegante, podenão, ao passo que o regulamento delegado se prende à lei dela. 
mas legais, em sentido formal, isto é, não prospere contra legem, cria direito nôvo, sem que se fundamente em lei que esteja regulando ou que lhe delegue competência para outras disciplinações intra legem, porque se alicerça na competência discricionária da Administração ${ }^{30}$, criando direito nôvo praeter legem.

PIETRO VIRGA ${ }^{31}$, por essa forma, fundamenta os regulamentos independentes:

... "vengono emanati per disciplinare l'esercizio delle potestà discrezionale che la legge attribuisce alla pubblica amministrazione.

Essi non si ricollegano ad una legge precedente da eseguire; tuttavia incontrano un limite specifico derivante dal fatto che la potestà regolamentare indipendente si estende nello stesso ambito in cui si estende la potestà discrezionale; quindi la norma che attribuisce una potestà discrezionale funciona anche per determinare la sfera entro la quale può svolgersi la potestà regolamentare indipendente" (grifou-se).

No mesmo sentido é a opinião de DUGUIT e muitos outros ${ }^{32}$, cuja transcrição se tornaria fastidiosa.

12. Não impressiona, data venia, a alegação de que as Constituições brasileiras apenas têm conferido ao Executivo - poder regulamentar restrito, concernente à expedição de simples regulamentos de execução, pela desenganada referência à atribuição, tão-sòmente, de baixar regulamentos "para a fiel execução das leis". Ora, como adverte MARCELLO CAETANO, ao comentar expressão semelhante da Constituição portuguêsa de 1933 ("para a boa execução das leis"), quando se fala em regulamento para a "fiel execução da lei" (ou "boa execução da lei"), não se quer dizer que o regulamento é uma regra destinada à execução de certa e determinada lei anterior. "A boa execução da lei (entre nós: a "fiel

30 GARCIA OVIEDO, ob. e vol. cits., págs. 223 e 224 , assim justifica os regulamentos independentes: "Emanam do poder discricionário inerente a tôda ação de govêrno, e se apóiam na impossibilidade em que se acha o Poder Legislativo (...) de atender aos problemas que quotidianamente se apresentam".

31 Ob. cit., pág. 392.

32 DUGUIT, Traité de Droit Constitutionnel, 2ạ ed., Paris, 1924, Tomo IV, $\S 48$, págs. 714 e 715; EMILIO CROSA, Corso di Diritto Costituzionale, Parte II, Turim, 1950, pág. 289; RAFAEL BIELSA, Principios de Derecho Administrativo, Buenos Aires, 1942, pág. 103. 
execução das leis") não é, pois, a execução de cada lei, mas a dinamização da ordem legislativa". ${ }^{33}$

A atual Constituição italiana, como bem expõe ZANOBINI ${ }^{34}$, não faz qualquer referência ao poder regulamentar, "limitando-se apenas a recordar, entre as atribuições do Presidente da República, a de baixar regulamentos" (art. 87), sem especificar de que natureza. Se se entendeu possível, no direito italiano, a emanação de regulamentos independentes, sem referência constitucional, expressa, como excluir da competência do Executivo, no Brasil, a faculdade de expedir tais regulamentos? É que o fundamento dos regulamentos independentes não é a expressa autorização constitucional, mas a competência discricionária.

13. Incontáveis foram os regulamentos independentes expedidos no país, bastando lembrar a reconhecida competência do Executivo para criar e extinguir, por decreto, cargos públicos nas autarquias, bem como fixar-lhes os respectivos vencimentos, desde a criação dêsses entes no Brasil; a criação de empregos nos órgãos da Administração Direta e Indireta, através de aprovação, por decreto, de tabelas respectivas; os chamados regulamentos de organização, que também são autônomos ${ }^{35}$, os de polícia, criação de embaixadas, consulados, etc. ${ }^{36}$.

Sendo os regulamentos de organização, como me parece irretorquível em relação a todos os regulamentos independentes ou autônomos, atos legislativos materiais, embora, como é evidente, sem o poder derrogatório ou revogatório de leis formais, pois que estas só se ab-rogam por outras da mesma fonte orgânica, podem criar órgãos permanentes, desde que pág. 95 .

33 Manual de Direito Administrativo, 8 a ed., Lisboa, 1968, tomo I, n? 44,

34 La Gerarchia delle Fonti nel nuovo Ordinamento, in Commentario alla Costituzione Italiana, dirigido por PIERO CALAMANDREI e ALESSANDRO LEVI, Florença, 1950, vol. I, pág. 55.

35 GARCIA OVIEDO, ob. e vol. cits., pág. 224.

36 O Dec. no 38.728 , de 30-1-56, Criou o Consulado em Wilmington, Carolina do Norte, E.U.A.; Dec. n? 42.553, de 30-10-57, Eleva à categoria de Embaixada a representação diplomática do Brasil em Copenhague; Dec. n? 43.424, de 26-3-58, Cria o Consulado do Brasil em Punto Fijo, Venezuela; Dec. n? 43.467, de 27-3-58, Cria a Legação do Brasil junto à Federação das Monarquias Árabes; Dec. no 43.463 , de 27-3-58, Eleva à categoria de Embaixada a representação diplomática do Brasil em Tel Aviv; Dec. no 45.962, de 4-5-59, Cria a Embaixada do Brasil no Vietnam do Sul, e um número infindável de outros, que tenho em mãos, criando órgãos, etc. 
se situem na esfera de competência do poder regulamentar, isto é, não disponham sôbre matérias que, na forma da Constituição, importem em competência privativa do legislador, como, por exemplo, a criação de impostos ou taxas, ou não violem princípios constitucionais ou legais em vigor, pois os regulamentos em geral podem ser secundum legem (de execução), intra legem (delegados) ou praeter legem (independentes), mas nunca contra legem.

Os regulamentos independentes mais se ligam à organização, funcionamento e atribuições de órgãos públicos, a disposições de polícia e outras que se possam situar no âmbito da competência discricionária.

14. Se se admitia a impugnação dos regulamentos independentes para os que, contra tôda a tradição regulamentar entre nós e no direito estrangeiro, não aceitavam a competência discricionária administrativa como fundamento de tal regulamentação, exigindo a referência constitucional expressa, esta, após a Emenda Constitucional no 1, de 17 de outubro de 1969, que deu nova redação à Constituição Federal, se encontra taxativamente indicada entre os atos de competência do Presidente da República. Veja-se 0 art. $81, n$ ? $V$, onde se estatui competir ao Presidente da República. "V. Dispor sôbre a estruturação, atribuições e funcionamento dos órgãos da administração federal". São os chamados regulamentos de organização, que se classificam entre os regulamentos independentes e sempre se entendeu atribuição livremente deferida ao Poder Executivo, ainda que no silêncio de qualquer disposição constitucional.

Já no Ato Institucional no 8, de 2 de abril de 1969, se autorizava o Poder Executivo a realizar reformas administrativas nos seguintes têrmos:

"Art. 2? Para possibilitar a realização da reforma administrativa, poderá o Poder Executivo, inclusive o da União, através de Decreto:

I - alterar a denominação de cargos em comissão;

II - reclassificar cargos em comissão, respeitada a tabela de símbolos em vigor;

III - transformar funções gratificadas em cargos em comissão;

IV - declarar a extinção de cargos." 
A competência, através de regulamentos autônomos, que apenas se reconhecia ao Poder Executivo em relação às entidades autárquicas, passou agora, por fôrça dêsse Ato Institucional, a exercer-se sôbre os cargos públicos da Administração Direta.

15. Os regulamentos independentes sempre se baixaram, entendidos como indispensáveis à dinâmica administrativa, pela sua fundamentação na competência discricionária, reconhecida pacificamente à Administração. O princípio da separação de podêres não pode ser entendido de maneira rígida, pois que, se assim fôsse, se emperraria a máquina administrativa, sem condições de atender ao desenvolvimento social e, já agora, ao grande progresso tecnológico, que impõe uma maior dinamização no gerir a coisa pública. 